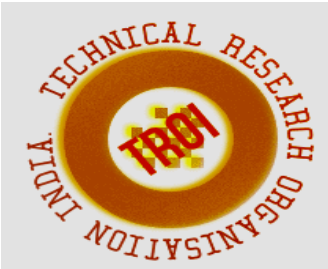

\title{
SHORT COURSES ELEARNING SYSTEM
}

\author{
Tabrej Khan ${ }^{1}$, Syed Asif Hassan ${ }^{2}$ \\ ${ }^{1}$ Department of Information Sciences, Faculty of Computing and Information Technology Rabigh \\ (FCITR), King Abdulaziz University, Jeddah, Saudi Arabia \\ ${ }^{2}$ Department of Computer Sciences, Faculty of Computing and Information Technology Rabigh \\ (FCITR), King Abdulaziz University, Jeddah, Saudi Arabia \\ EMAIL: tkamin@kau.edu.sa ${ }^{1}$, shassan1@kau.edu.sa²
}

\begin{abstract}
E-Learning has become a necessity in the current education system. E-learning has made it easier for the student and teacher to communicate in a lesser amount of time and with little effort. With the progress and the enormous development of distance education there is a need for a dynamic website that allows students and teachers to take all the advantages of courses in vibrant areas . Therefore, Online Short courses eLearning system is a web application specially designed for Students and teachers to enable effeicent learning. After reviewing the ongoing teaching and learning process in the various universities, we found the need for Online Short courses eLearning system and we strongly recommend it with a view to eradicate several internal intricacies involved in e-learning process.
\end{abstract}

The website allows students to view and register short courses online conducted by instructors also they can see courses starting dates, finishing date and locations. It also allows the instructor to put things on his courses on the site and see the students enrolled in the study material. Finally, the student can print the certificate after finished the course online. ASP.NET, SQL SERVER, JavaScript SQL SERVER Database will use to develop the FCITR Online Short courses Subscribe system.

Keywords: e-learning, Short Courses, ASP.NET, SQL SERVER

\section{Introduction}

In the recent year development progress in every walk of life has been accelerated by the internet and its power of implementation of new ideas in education industry pay more attention and tremendous potential benefits. Many university or colleges they apply the online system to eliminate the obstacle during teaching activities and remove the hassle between teacher and students [1-3].

The first time in 1990 North America introduced the concept of eLearning based on the internet. Which is totally changed the concept of learning method or teaching process. Different types of open source and content management systems are used for the e-learning system [4-5]. Which is able to manage, organize, present, and evaluate the content of courses and teaching process. It helps teachers and students to browse the content, evaluate the education system within the university [6-7].

Moodle is an open-source learning system which is available free of cost [8]. Blackboard is also an eLearning system but at a high price. Still, this type of system has many problems first it is hard to implement to all teachers and students with a traditional teaching environment.it is not supported by short courses with certificate generation [9].

In this regards our proposed short courses subscribe eLearning system has the following advantages 1)students can pursue some short courses which is job oriented 2) Instructor can easily upload course materials, attendance. 3) It is a direct link between instructor and students 4) Students can easily download course-related materials, view attendance and after finishing, the course students are able to print a certificate online. 5) This system is a center for knowledge resources.

This paper structured in a different section as follows: Section I Describe the material and method used to develop the Short courses 
Subscribe eLearning system. Section II explains the Result and discussion of the Short courses Subscribe eLearning system and Section III provides the concluding statements about the developed Short courses Subscribe eLearning system.

\section{MATERIAL AND METHOD}

To develop the Short courses Subscribe the eLearning system as shown in figure 1 . It is a sequential process. First phase deal with problem identification in ongoing teaching process for short courses followed by next phase i.e. requirement analysis includes analysis of current teaching system and problem, proposed solution and model.in the next phase i.e. is designing phase include UML diagram like use case diagram, entity-relationship (ER) diagram etc. followed by the next phase 1.e is implementation deals with coding and user interface design. The proposed system developed in visual studio with the c\# programming language and SQL Server Database [10-12].

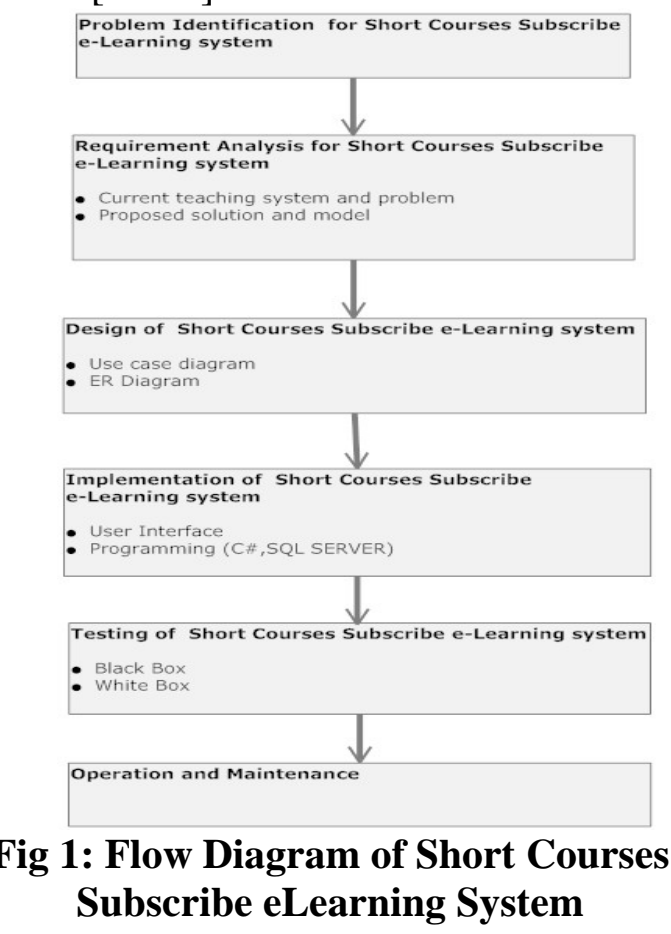

Finally, the function of the proposed system was tested using black-box and white box testing methods. This application is finally operational in the faculty of information system (FCITR), Rabigh for short courses.

\section{RESULTS AND DISCUSSION}

A. Short courses subscribe eLearning system design

a) A use case diagram for Short courses subscribe eLearning system: Use case diagram for Short courses subscribe eLearning system used to represent a graphical overview of the functionality provided in the system in terms of actors, functions, and dependencies between use case and actors as shown in figure 2. This diagram includes three actors namely Learner, instructor and admin.there are 15 use cases associated with actors. The learner can log in to the website after registration.later on learner can view the different short courses and can register on courses. After registration, the course learner can view attendance, download course-related materials and finally print the certificate. Additionally, the instructor can manage course details, manage course materials, manage attendance related to courses, manage registered users and generate the certificate. Finally, admin can approve students and instructors, view and manage the course, manage instructors and students details and assign a student in the course [13].

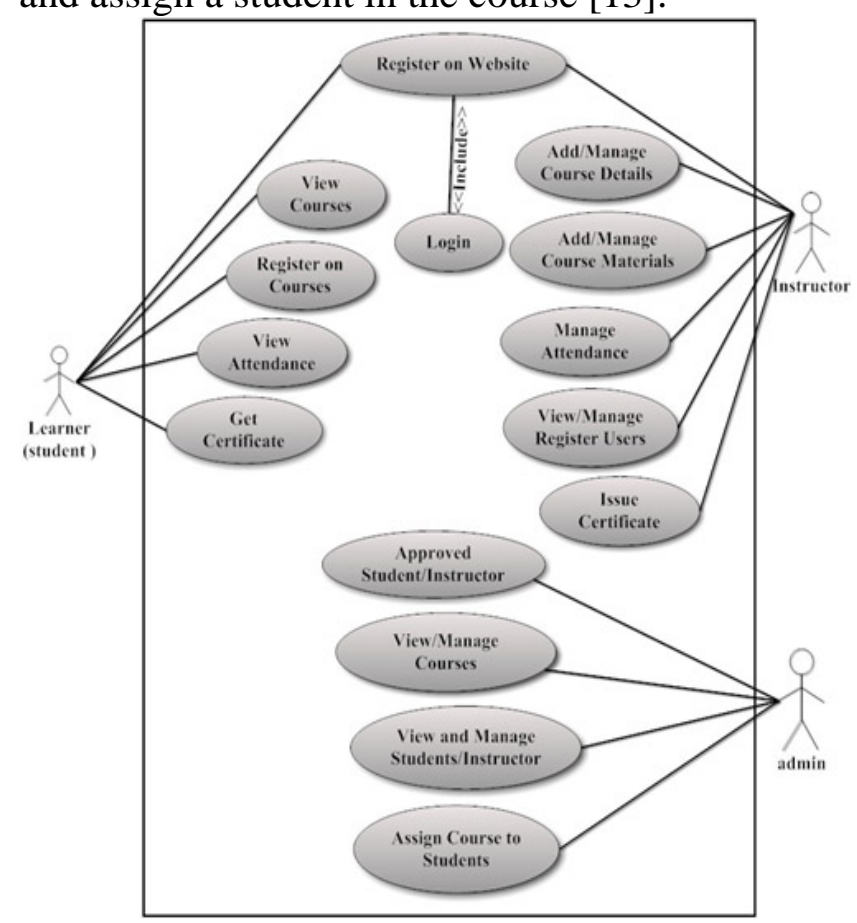

Fig 2: Short Courses Subscribe eLearning System Use Case

b) ER diagram for Short courses subscribe eLearning system: and Tables: In ER diagram have seven entity namely 1)Student 2)admin 3)certificate 4)Attendance 5)courses 6)Course Materials and 7)Instructor. Each entity has 
attributes and relationship as shown in figure 4.as As shown in figure 4 instructor can teach any courses. On the other hand, the student can join any courses. Additionally, the student can download course materials, print certificates, and view attendance[8].

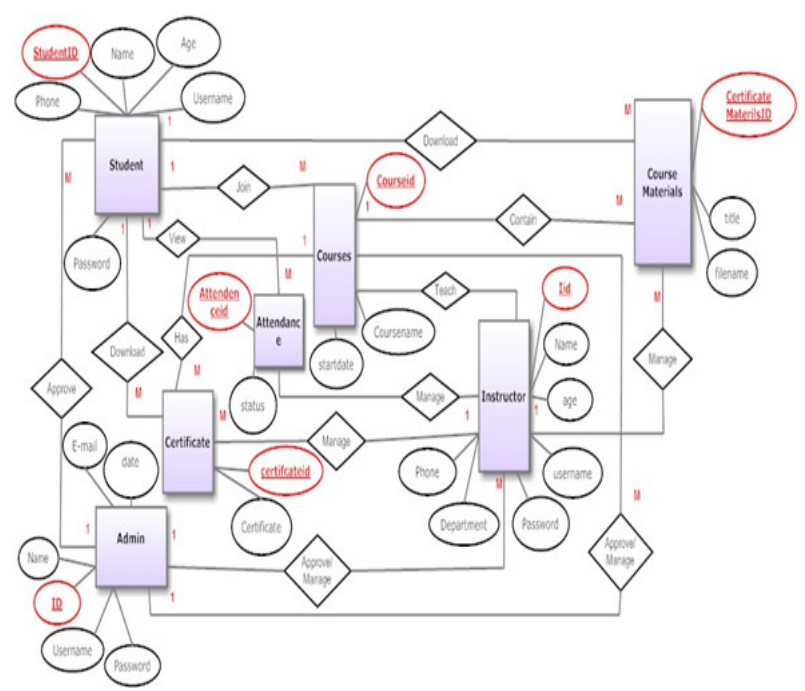

Fig 3: Short Courses Subscribe eLearning System ER

B. Short courses subscribe to eLearning system implementation

a) Short courses subscribe eLearning system Login page: After registration learner and student can log in with username and password also admin can $\log$ in as shown in figure 4

\section{FCITR SHORT COURSES SUBSCRIBE SYSTEM}
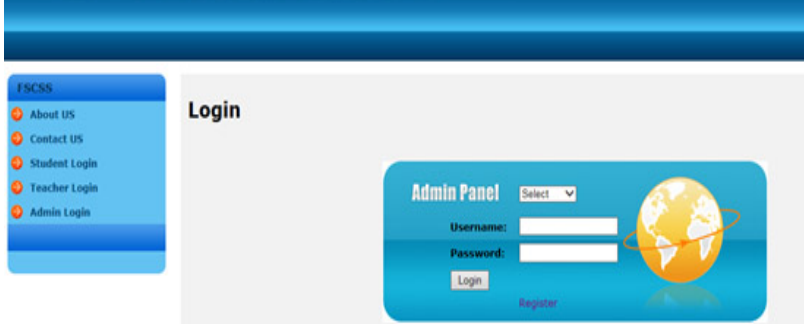

Fig 4: Short Courses Subscribe eLearning System Login page

b) Short courses subscribe eLearning system Join Course page: In this web, page learner can register in course as shown in figure 5

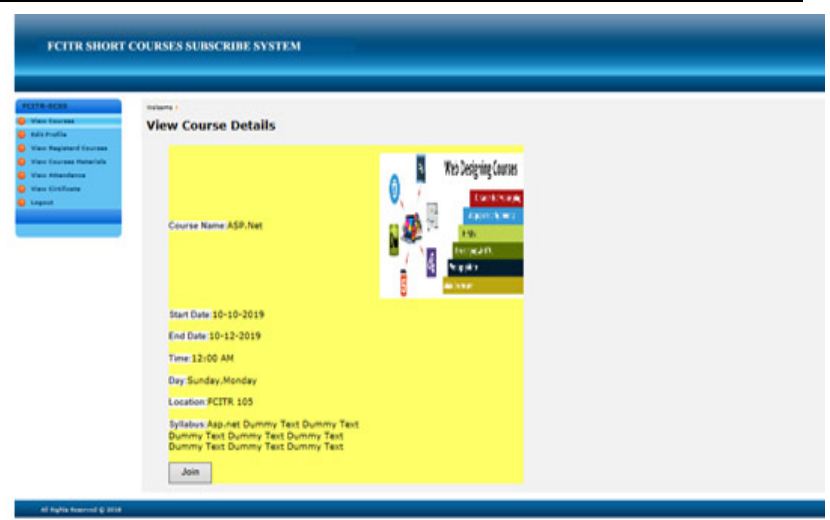

Fig 5: Short Courses Subscribe eLearning System Join Course page

c) Short courses subscribe eLearning system Download Course Materials page: This web page for learner where the learner can download course materials for registered courses as shown in figure 6

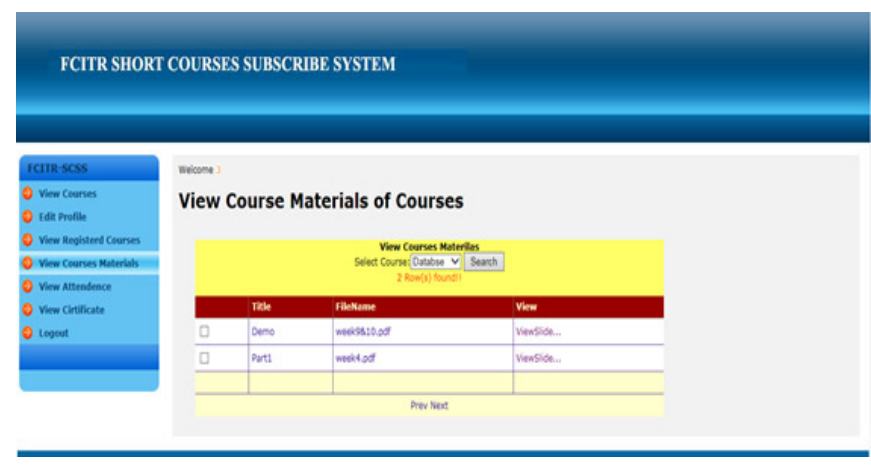

Fig 6: Short Courses Subscribe eLearning System Download Course Materials page

d) Short courses subscribe eLearning system View Attendance page: This web page learner can view attendance for the registered course as shown in figure 7

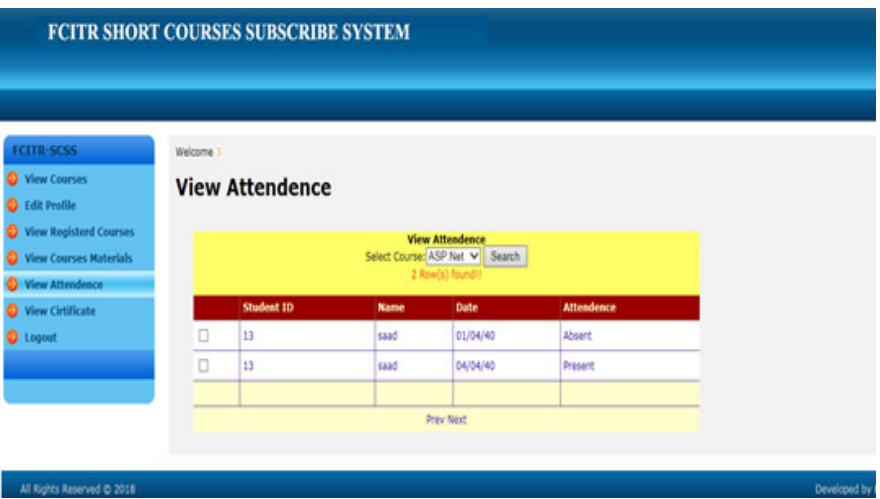

Fig 7: Short Courses Subscribe eLearning System View Attendance page 
e) Short courses subscribe eLearning system Download Certificate page: This webpage learner can download the certificate after completion of course as shown in figure 8

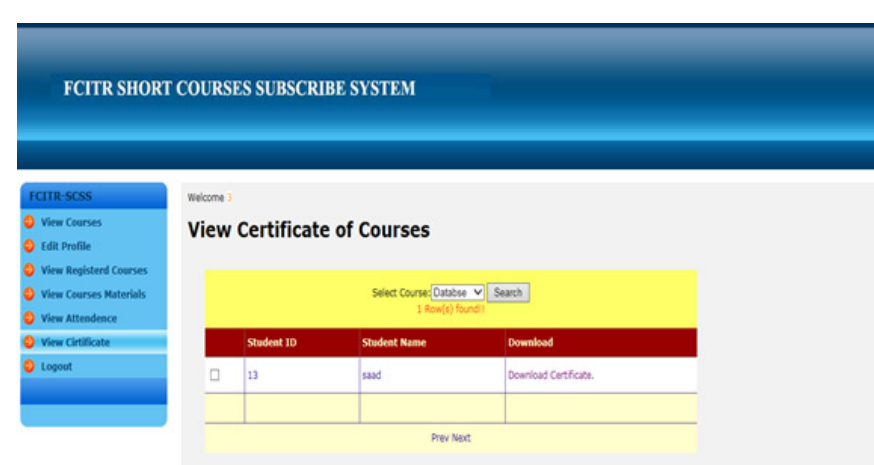

Fig 8: Short Courses Subscribe eLearning System Download Certificate page

f) Short courses subscribe eLearning system Add Course Details page: In this web, page instructor can add a new short course for the learner as shown in figure 9

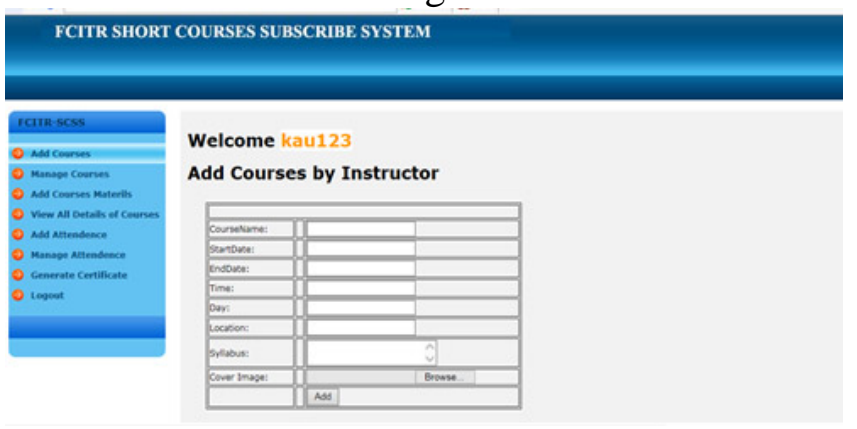

Fig 9: Short Courses Subscribe eLearning System Add Course Details page

g) Short courses subscribe eLearning system Add Course Materials page: In this web, page Instructor can add course materials for a learner like a slide, tutorials, etc. as shown in figure 10

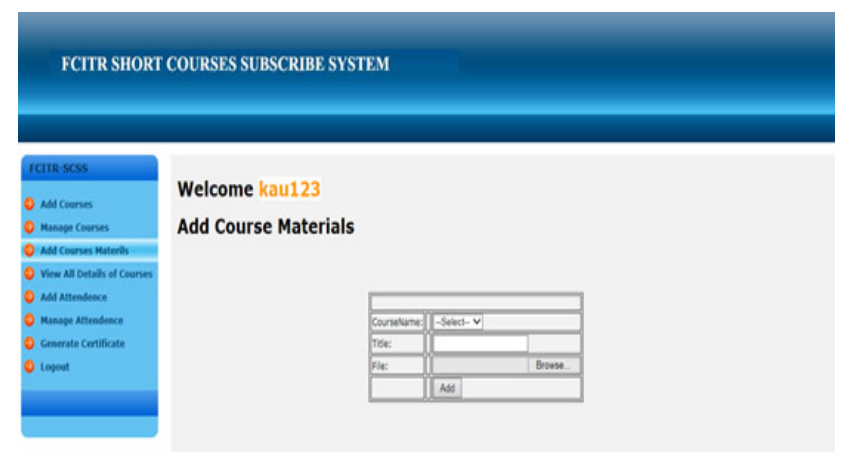

Fig 10: Short Courses Subscribe eLearning System Add Course Materials page h) Short courses subscribe eLearning system Add Attendance page: Place after In this web page instructor can take attendance on a class date as shown in figure 11

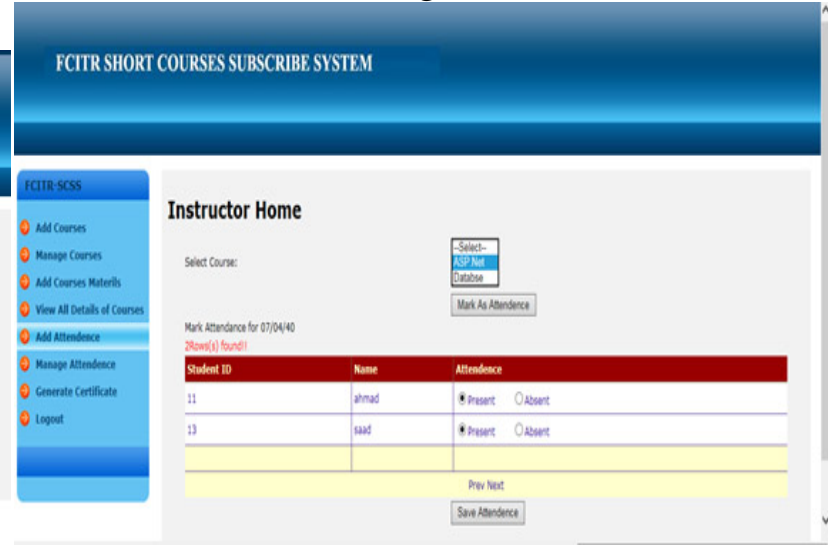

Fig 11: Short Courses Subscribe eLearning System Add Attendance page

i) Short courses subscribe eLearning system Generate certificate page: Place after in this web page instructor can generate a certificate for learner after finish the course as shown in figure 12
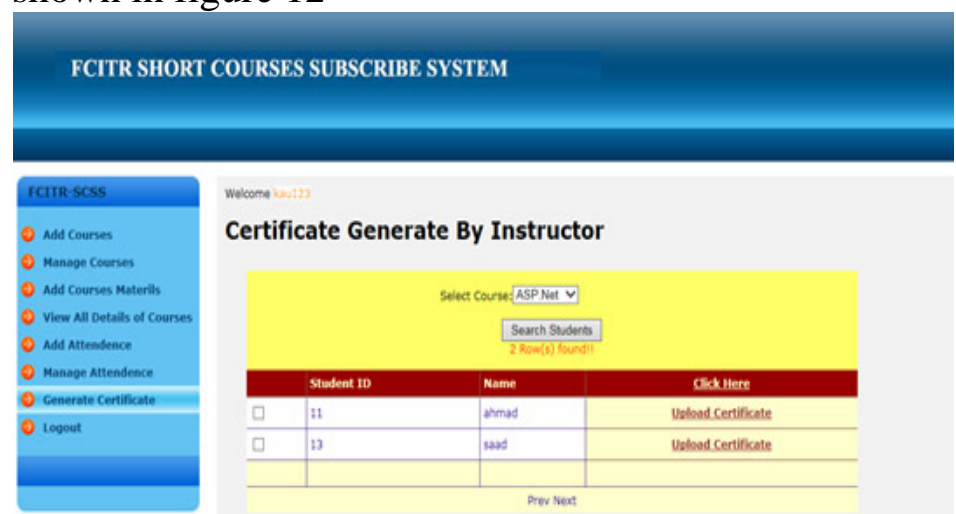

\section{Fig 12: Short Courses Subscribe eLearning System Generate Certificate page}

\section{CONCLUSION}

Short courses subscribe eLearning system is good for an academic institution where Instructors providing short courses in the traditional way where instructors published course information on the notice board.to register the short courses student will contact the instructor, sometimes the instructor is not available in the office also after completion of courses again a student has to communicate with the instructor. These traditional ways are time-consuming. Therefore by applying our present application i.e., Short courses subscribe eLearning system short courses manage in a perfect way so students and an instructor can save time and effort. 


\section{ACKNOWLEDGMENT}

The authors thank the administration and especially the dean of FCITR for providing the facilities to carry out this work.

\section{REFERENCES}

[1] Z. Zhang, "Design and Implement of WebBased Intelligence Network Tutoring Framework Model”, Distance Educational Journal, 2004, vol. 4, pp. 35-37.

[2] A.F. Elgamal, H.A. Abas, E.S.M. Baladoh, An interactive e-learning system for improving web programming skills, Educ. Inf. Technol. 18 (2013) 29-46. https://doi.org/10.1007/s10639-011-9175-7.

[3] J. Štěpánek, M. Šimková, Design and Implementation of Simple Interactive elearning System, Procedia - Soc. Behav. Sci. $83 \quad$ (2013) 413-416. https://doi.org/10.1016/j.sbspro.2013.06.08 1.

[4] S. Ghoniemy, A. Fahmy, S. Aljahdali, A Dedicated Web-Based Learning System, J. Comput. Sci. Eng. Technol. 1 (2010) 8492.

[5] R. Joshi, V. V Shete, S.B. Somani, Android Based Smart Learning and Attendance Management System, Int. J. Adv. Res. Comput. Commun. Eng. 4 (2015) 256-260.
https://doi.org/10.17148/IJARCCE.2015.46 55.

[6] M.J. Mosa, I. Albatish, S.S. Abu-Naser, ASP.NET-Tutor: Intelligent Tutoring System for leaning ASP.NET, Int. J. Acad. Pedagog. Res. 2 (2018) 1-8.

[7] K. Sridharan, A course on web languages and web-based applications, IEEE Trans. Educ. $\quad 47 \quad$ (2004) 254-260. https://doi.org/10.1109/TE.2004.825228.

[8] The Moodle web site, http://moodle.org/

[9] B. Beatty, C. Ulasewicz, Faculty Perspectives on Moving from Blackboard to the Moodle Learning Management System, TechTrends. $50 \quad$ (2006) 36-45. https://doi.org/10.1007/s11528-006-0036-y.

[10] I. Sommerville, "Software Engineering," 9th ed., Pearson, 2010.

[11] X. Zhu, H. Zhao, Appl. Econ. Bus. Dev., Springer Berlin Heidelberg,pp. 170-176, 2011.

[12] N.M.A. Munassar, and A. Govardhan, "A Comparison between Five Models of Software Engineering,” Int. J. Comput. Sci. vol. 7, pp. 94-101, 2010.

[13] A.Y. Mahmoud, M.S. Barakat, M.J. Ajjour, Design and development of elearning university system, J. Multidiscip. Eng. Sci. Stud. 2 (2016) 498-504. 